\title{
O D. N. C. perante a Constituição
}

\author{
Dr. A. de Sampaio Doria
}

A consulta que me vem de S. Paulo, versa sobre os itens seguintes :

$10^{\circ}$ - Qual, em face do $\S 3 .^{\circ}$, artigo $60^{\circ}$, das Disposições Transitorias da Constituição, a taxa em vigor sobre a exportação do café.

$20^{\circ}$ - A quem incumbe, em vista da mesma dispo= sição constitucional, arrecadar a taxa que tiver de ser.

3. - Sempre em obediencia ao imperativo da lei, qual a situação constitucional do Departamento Nacio= nal do Café.

O artigo $6 .^{\circ}$, § $3 .^{\circ}$, das Disposições Transitorias, dispõe:

“As taxas sobre exportação, instituidas para a defesa de produtos agricolas, continuarão a ser arrecadadas, até que se liquidem os encargos a que elas sirvam de garantia, respeitados os compromissos decorrentes de convenios entre os Estados interessados, sem que a importancia da arrecadação possa, no todo ou em parte, ter outra aplicação; e serão reduzidas, logo que se solvam os debitos em moeda nacional, a tanto quanto bastem para o serviço de juros e amortização dos emprestimos contraídos em moeda estrangeira".

E' o que está em vigor desde 16 de julho. Não se trata, ai, de recomendação paternal, de mandamento doutrinario, 
ou de preceito adiavel. Mas de uma determinação incisiva e peremptoria, com que se entendeu encerrar a politica de defesa do café. Nem é preciso votar o Congresso lei ordinaria, para que possa ser executado o $\S 3 .^{\circ}$, artigo $6 .^{\circ}$ das Disposições Transitorias. Bastam providencias de carater administrativo, de exequibilidade imediata, e que já tardam.

Vejamos.

O texto constitucional, acima transcrito, envolve, na sua ampla contextura, varias disposições entrelaçadas, a compreensão exata de cada uma das quais nem sempre se logra a uma primeira leitura. Desdobra-se o texto:

$1^{\circ}$ ) As taxas sobre a exportação, instituidas para a defesa de produtos agricolas, continuam a ser arrecadadas.

2..$^{\circ}$ Essas taxas cessam de todo, quando se liquidarem os encargos a que sirvam de garantia.

$3 .^{\circ}$ Logo, porém, que se saldem os debitos em moedas nacional, serão reduzidas a tanto quanto bastem ao serviço de juros e amortização dos emprestimos contraidos em moeda estrangeira.

$\left.4 .^{\circ}\right)$ Serão respeitados os compromissos decorrentes de convenios entre os Estados interessados.

5..$^{\circ}$ E, finalmente, não póde a importancia da arrecadação das taxas ser, desde 16 de julho, aplicada, no todo, ou em parte, senão para liquidar os encargos que a elas sirvam de garantia.

Examinemos, uma a uma, as clausulas, acima desmembradas, do imperativo constitucional.

Preliminarmente, porém, passemos revista ao que ha sobre os convenios cafeeiros, e nos inteiremos da genese e da natureza do Departamento Nacional do Café, de como nasceu e o que é. 


\section{Os convenios}

O magno problema, o problema torturante, do café tem sido a busca, não raro angustiosa, do equilibrio entre a sua oferta e a sua procura. Em logar de deixar a solução do caso ao jogo das leis economicas, entenderam, obstinadamente, os poderes publicos, entre nós, intervir, com maior ou menor artificialidade, em defesa dos preços não sò instaveis, mas em quéda até ás vezes abaixo do custo de produção.

Daí, os convenios de defesa do café, a começar pelo de Taubaté, em 1906, entre S. Paulo, Minas e Rio. Já então, para executar o plano, ficou o Estado de S. Paulo autorizado a contrair, com a garantia de uma sobretaxa de tres francos, emprestimo de 15 milhôes de libras.

Os convenios, porém, a que se refere o $\S 33^{\circ}$, do artigo 6. citado, não são o de Taubaté, nem os sucessivos até o 5..$^{\circ}$, de 1 de setembro de 1930. Mas os recentes, os da época revolucionaria. Os outros, a ela antecedentes, já se consumaram em todos os seus efeitos.

\section{Primeiro convenio}

Em 1931, aos 24 de abril, acordaram São Paulo, Minas, Rio de Janeiro, Espirito Santo e Paraná, taxar, com meia libra esterlina, a exportação de cada saco com 60 quilos de café. Os fundos obtidos com esta arrecadação, estatuia a clausula $4 .^{\mathrm{a}}$ do primeiro convenio "serão aplicados, exclusivamente, na compra, para eliminação, dos excessos da produção e dos estoques", que havia, incluindo-se, entre as despesas inerentes a essas compras, as da manutenção do Conselho que o Convenio instituia, assim como a dos serviços que the estivessem a cargo, ou lhe fossem atribuidos.

Na clausula 6.a deste convenio, se criava um "Conselho dos Estados Cafeeiros", autonomo, com personalidade juridica, e séde no Distrito Federal. 
Decretos de 27 de abril dos Estados interessados ratificaram o convenio de 24 , aprovado, por sua vez, pelo governo federal, em 16 de maio de 1931.

\section{Segundo convenio}

A 30 de novembro do mesmo ano, os Estados de S. Paulo, Minas, Rio, Espirito Santo, Paraná, Bahia, Pernambuco e Goiaz, celebraram outro convenio, em que compromissos novos eram tomados. Maior era o numero dos comprometentes. E, entre os compromissos novos, ressalta o aumento para 15 shillingś-ouro da taxa por saco de café que se exportasse.

"Da taxa de exportação aqui referida (reza a clausula 4." do segundo convenio) 10 shillings continuarão a ser cobrados sem alteração do processo em vigor, e sua aplicação será a mesma prevista no convenio de 24 de abril. Os 5 shillings-ouro, majorados, serão cobrados em cheques á vista sobre Nova-York ou Londres, á ordem do Conselho Nacional do Café e aplicados exclusivamente no serviço do emprestimo de $£ 20.000 .000$, contraido, em 1930, pelo Estado de São Paulo, com os banqueiros J. H. Schroeder \& Cia.".

E preceitua a clausula $13 .^{a}$ do mesmo convenio:

"O saldo que s everificar no patrimonio do Conselho, por ocasião de sua extinção, decorrente das sobras da arrecadação da taxa de 10 shillings, ou da renda dos stocks, ou de outras fontes de renda, excluidos os recursos decorrentes da taxa de 5 shillings, terão o seguinte destino: pagamento das prestações restantes do emprestimo de $£ £ 20.000 .000 "$ ".

Tambem este segundo convenio foi ratificado pelo Estado de São Paulo, no decreto n. 5.278, de 7 de dezembro de 1931.

O "Conselho dos Estados Cafeeiros", criado pelo primei- 
ro convenio, passou, pelo segundo, a denominar-se "Conselho Nacional do Café".

E tambem a União, que não quiz nunca alheiar-se do problema, aprovou o segundo convenio no decreto n. 20.760, de 7 de dezembro de 1931. Vale a pena trascrever o art. 2. desse decreto:

"Art. 2. - Fica aumentada para 15 shillings a taxa de 10,0 sobre cada saco de 60 quilos de café exportado, criada pelo convenio de 25 de abril e pelo decreto $n$. $^{\circ}$ 20.003, de 16 de maio, tudo do corrente ano.

$\S 10^{\circ}$ - 0 aumento de 5 shillings-ouro, a que se refere este artigo, será arrecardado em cambiais á vista sôbre Nova-York ou Londres, no momento da exportação, pelo Conselho Nacional do Café, e especialmente escriturado, não podendo ter outra aplicação que não a prevista no texto do convenio óra aprovado.

$\S 20^{\circ}-$ Os 10 shillings restantes continuarão a ser cobrados na forma já adotada para a sua arrecadação".

\section{Departamento Nacional}

Logo depois, dá-se um quasi terremoto. E' o Conselho Nacional de Café substituido por um Departamento Federal, solenemente criado pelo decreto n. 22.452 , de 10 de fevereiro de 1932 , cujo art. $10^{\circ}$ está redigido:

“Art. 1. - Fic criado o Departamento Nacional do Café, subordinado ao Ministerio da Fazenda, e extinto o atual Conselho Nacional do Café".

E, para melhor lhe acentuar a natureza federal, dispoz o art. $2 .^{\circ}$ :

“Art. 2. - A direção do Departamento será exercida por três diretores, livremente nomeados pelo Governo Federal, cumprindo-lhes agir sob a superintendencia do Ministerio da Fazenda". 
Com o Departamento Nacional, que extinguiu o Conselho, por onde os Estados orientavam a politica do café que produziam, chamou a União a si, soberanamente, a defesa economica deste produto, em todo o país.

Traça o Regulamento de 23 de fevereiro de 1933 ao Departamento Nacional do Café as seguintes caracteristicas:

$10^{\circ}$ - Autonomia administrativa e financeira;

2..$^{\circ}$ - Jurisdição, no que concerne á execução dos serviços a seu cargo, em todo o territorio nacional;

3. - Duração que deveria ter o extinto Conselho Nacional do Café.

E' o que estatue claramente, palavra por palavra, o art. 1. ${ }^{\circ}$ do Decreto que regulamentou o Departamento:

“O Departamento Nacional do Café, criado pelo Decreto $\mathrm{n}$. 22.452, de 10 de fevereiro de 1933, subordinado ao Ministerio da Fazenda, e com autonomia administrativa e financeira, tem jurisdição, no que concerne á execução dos serviços a seu cargo, em todo o teritorio nacional e terá a duraçẫo que deveria ter o extinto Conselho Nacional do Café".

Ora, o extinto Conselho Nacional do Café, diz o art. 1. ${ }^{\circ}$ do seu Regulamento, “é o mesmo Conselho dos Estados Cafeeiros, criado pelo convenio de 24 de abril". E, por este convenio, a taxa de exportação, sangue, vida e força motora do Conselho, só poderia ser mantida, no maximo, até abril de 1935. Textualmente:

"Esta taxa especial será arrecadada durante o prazo maximo de quatro anos, a contar das datas dos decretos de ratificação deste acôrdo, expedidos pelos governos dos Estados interessados".

E, para dissipar qualquer duvida sobre o proposito dos Estados que criaram a taxa, reforça a clausula $2 .^{a}$ do convenio: 
"Findo esse prazo, ficará a mesma suprimida, independente de qualquer acto dos Estados que a tiverem decretado, os quais, em caso algum, poderão incorporala á sua receita".

A 27 de abril do mesmo ano, os Estados interessados expediram decretos ratificando o convenio.

Logo, a 27 de abril de 1935, quatro anos depois de instituida, já não podia existir, com lealdade, a taxa de exportação sobre o café. E, como o Conselho era o órgão criado para arrecadar e aplicar a taxa, e para mais nada, suprimida a taxa, logicamente deixaria de existir o Conselho. E como o Departamento Nacional do Café tem a duração do Conselho, deixará ele, na lei que o gerou, de existir a 27 de abril de 1935.

Até lá, se nenhuma lei o impedisse, poderia exercer as funções para as quais foi criado.Entre estas funções, resaltam:

1..$^{\circ}$ arrecadar a taxa de 15 shillings por saco de café que se exportar, promovendo o recolhimento dessa taxa ao Banco do Brasil;

1.) aplicar as quantias arrecadadas:

a) na comprà de café para eliminação, ou quaisquer outros fins, tendentes ao equilibrio dos mercados, e à defesa econômica do produto;

b) na remessa das quantias necessarias ao serviço de juros e amortização do emprestimo de 20.000.000 de libras, contraido pelo Estado de São Paulo;

c) no custeio de todos os seus serviços, inclusive os referentes á melhoria da produção, á estimativa das safras, á liberação das quotas de embarque e entregas diarias aos mercados exportadores.

Prevenindo protestos que não deixariam de aparecer, e para tranquilidade geral dos interessados, o n. 6 , art. "4. do Regulamento impoz ao Departamento que disciplinava, 
essa obrigação insofismavel, obrigação cujo desrespeito teria sido imperdoavel:

\begin{abstract}
"Remeter, mensalmente, ao Ministerio da Fazenda, balancete minucioso da arrecadação da taxa de 15 shillings, discriminando as verbas da sua aplicação, os saldos em caixa, o total dos sacos de café comprados: eliminados ou utilizados, e em stock".
\end{abstract}

Assinalemos, ainda, para melhor compreender as conclusões a que vamos ter, um aspeto sobre a natureza do Departamento Nacional do Café, como pessoa juridica. E' o que estatue o $\mathrm{n} .8$ do art.4.$^{\circ}$ do Regulamento, quando atribue ao Departamento:
"Orientar todos os seus serviços de modo pratico e eminentemente tecnico, nomeando e demitindo os seus funcionarios e servidores e fixando-lhes os vencimentos e salarios".

O Departamento Nacional do Café não é uma repartição publica. E' um instituto com personalidade juridica, a cujo presidente cabe a sua representação ativa e passiva em juizo, ou fóra dele. E' um instituto dotado de capacidade para contratar, e a que se impoz assinar qualquer outro diretor com o presidente os contratos que tivesse de fechar. Os funcionarios do Departamento não são, pois, funcionarios publicos, mas empregados de uma pessoa juridica. A receita do Departamento não entra para o Thesouro como receita federal, mas é depositada no Banco do Brasil, á disposição da diretoria do Departamento, sob o olhar vigilante do Ministro da Fazenda.

Mas é uma pessoa juridica sui-generis, porque as suas determinações imperam como leis. Não é fundação, a cujos requisitos não satisfaz, nem associação de qualquer natureza, pois não tem associados. E' uma entidade juridica, com autoridade de imperio, que o poder politico lhe outorgou, e a este, que lhe deu vida, e lhe dá morte, subordinado, para lhe prestar, mez a mez, contas minuciosas de sua gestão. 
Pessoa juridica, que não seja fundação, e que não seja associação; pessoa juridica com poderes não permitidos á fundações nem ás associações civis ou comerciais, que é afinal ou que poderá ser? Entidade autarquica, que o direito administrativo vai admitindo, para exercer sem a responsabilidade imediata do Estado, mas em beneficio coletivo, atribuições de imperio?

Seja qual fôr a sua natureza, juridica, certo é que o Departamento do Café é uma criação do governo federal, que extinguiu os Convenios firmados pelos Estados.

\section{Os compromissos entre os Estados}

Antes ainda de prosseguir no exame do texto constitucional, que, hoje, regula soberanamente o assunto, extractemos, como preliminar, quais "os compromissos decorrentes de convenios entre os Estados interessados", cujo respeito a Constituição ordena.

Os convenios, a que se referem as Disposições Transitorias, não são o de Taubaté nem os anteriores a 1930. Mas o "Acôrdo" selado aos 24 de abril de 1931, por S. Paulo, Minas, Rio, Espirito Santo e Paraná, e o "Convenio" celebrado aos 5 de dezembro de 1931 por estes Estados, e, mais, Bahia, Goiaz e Pernambuco.

Do primeiro decorrem os compromissos seguintes:

1. - Taxar com meia libra a exportação de cada saco de café de 60 quilos, até abril de 1935.

2. - Só aplicar essa taxa na compra do café, para eliminar os excessos de sua produção, e no custeio do Conselho.

3. - Separar, do café comprado para eliminação, cem mil sacos, que o Instituto de Café de São Paulo empregaria em propaganda.

$4 .^{\circ}$ - Cessar a taxa de exportação aos 27 de abril de 1935, independente de qualquer acto dos Estados que a tenham decretado. 
5. - Não incorporar, em caso nenhum, a taxa de exportação ás receitas dos respectivos Estados.

Do segundo convenio, decorrem novos compromissos, como:

$10^{\circ}$ - Elevar de 10 para 15 shillings-ouro a taxa ide exportação.

2. - Só aplicar os 5 shillings acrescidos no resgate do emprestimo de 20 milhões, contraído pelo Estado de São Paulo com os banqueiros J. H. Schroeder \& Cia.

$3 .^{\circ}$ - Passar a responsabilidade do emprestimo de 20 milhões do Thesouro de São Paulo para o Conselho Nacional do Café.

4. - Pagar o Conselho os estoques de café, retidos em 30 de junho de 1931 e adquiridos com recursos de emprestimos.

5..$^{\circ}$ - Poder o Conselho realizar, a titulo de antecipação sua receita, quaísquer operações de credito em moeda nacional.

6. - Exercer o Conselho, em todo o país, o contraste sobre a produção, o transporte, o comercio e o consumo do café.

$70^{\circ}$ - Sustentar o Conselho a cotação do café então em vigor.

8. - Depositar o Conselho os fundos que tiver, no Banco do Brasil, e parte, cujo limite foi fixado, em Bancos oficiais dos Estados interessados.

$90^{\circ}$ - Restituir a cada Estado, na medida da contribuição respetiva, o excesso dos 5 shillings sobre os juros e amortização do emprestimo de 20 milhões.

$100^{\circ}$ - Aplicar o saldo do patrimonio do Conselho, ao se extinguir, no pagamento das prestações, que ainda restarem, do emprestimo de 20 milhões".

Afóra estes, outros de menor importancia.

Que é, de taes compromissos, o que, hoje em dia, ainda resta de pé? 
0 decreto n. 22.452, de 10 de fevereiro de 1933, extinguindo o Conselho Nacional do Cafè, e criando o Departamento Nacional, dispoz no seu artigo $5 .^{\circ}$ :

"Ao Departamento compete... receber as instalações e continuar os serviços do extinto Conselho Nacional do Cafiè".

Não parece que esse decreto, deflagrado de autoridade soberana, ditou lei nova, passando uma esponja por sobre os convenios?, e apagando os compromissos a que, neles, os Estados se obrigavam? Em logar deles, ditou ordens novas o poder discricionario, que imperou até a instalação da Constituinte. Em rigor, pois, não ha mais, propriamente, "compromissos decorrentes de convenios entre os Estados interessados".

Uma vez, porém, que fala a Constituição na existencia deles, vejamos quais poderiam ser.

Dos compromissos exarados nos convenios, se hão de excluir, primeiro, aqueles cujos efeitos já se consumaram, ou perderam sua razão de ser. E, depois, ainda, os que contravierem o texto constitucional, a cuja analise estamos procedendo. Parece que, em linhas iguais, subsistem os seguintes.

O primeiro seria a subrogação, para o Departamento do Café, do emprestimo de vinte milhões.

0 segundo seria que, para o resgate desse emprestimo, os Estados interessados consentem em taxar, com 5 shillings, a exportação de cada saco de café.

0 terceiro seria restituir aos Estados comprometentes, na proporção do que tiverem contribuido, as sobras da taxa dos cinco shillings.

O quarto seria aplicar o saldo que se verificasse no patrimonio do Departamento ao se extinguir, no pagamento antecipado do resto dos 20 milhões emprestados.

A manutenção, aliás, destes compromissos se ha de entender com as restrições e as ampliações da lei constitucional. 
E os demais? Por exemplo: a aplicação da taxa de dez shillings na compra de café, para equilibrar a oferta com a procura? Não é este um dos "compromissos decorrentes dos convenios", e, pois, um daqueles cuja vigencia a Constituição ordena que se respeite?

\section{Examinemos.}

$\mathrm{O}$ art. $6 .^{\circ}, \S 3 .^{\circ}$, das Disposições Transitorias da Constituição, foi elaborado para dominar as relações juridicas do assunto. Certo, ninguem tem duvidas a respeito disto. Logo, go, os compromissos dos Estados, cujo respeito a Constituição endossou, são os que possam viver, lado a lado, com as suas determinações. E uma destas determinações, clara, imperativa, é que não pode a importancia da arrecadação da taxa ser aplicada, no todo, ou em parte, senão no resgate do emprestimo, a que a taxa sirva de garantia. Comprar café para queimar, ou para vender, ou para propagar, não é resgatar emprestimo. Logo, semelhante compromisso, sobre não figurar entre os mantidos, foi pela Constituição anulado.

O caso não é unico. Outro dos compromissos, e dos mais solenes, foi o de que a taxa de exportação acabaria por inteiro aos 27 de abril de 1935 . Já o vimos. E' compromisso de honra entre os Estados cafeeiros. Dir-se-á que tambem esse entra na lista dos que devem ser respeitados?

Mas é o artigo $6 .^{\circ}, \S 3 .^{\circ}$, das Disposições Transitorias que estatue, logo de entrada, cousa diversa. Ordena que as taxas continuarão a ser arrecadadas, até que se liquidem os encargos a que sirvam de garantia. Não mais até 27 de abril de 1935. Mas até que se liquidem os encargos a que sirvam de garantia.

Em tais casos, quando o compromisso contravem a Constituição, claro está que cede ele o passo ás determinações constitucionais.

Em verdade, pois, o que a Constituição prescreve, é o respeito aos compromissos que não colidirem com os seus imperativos, e muito especialmente com o artigo $6 .^{\circ}$, $\S 3 .^{\circ}$, das Disposições Transitorias. 


\section{O que ordena a Constituição}

Isto posto, encaremos, face a face, o texto constitucional.

"As taxas sobre exportação, instituidas para a defesa de produtos agricolas, continuarão a ser arrecadadas".

Quer dizer que a Constituinte ratificou a instituição da taxa de exportação do café: "continuarão a ser arrecadadas". Estavam sendo, e continuam a ser arrecadadas. Manteve a Constituição a taxa de exportação do café. Até aqui, nenhuma duvida.

A' oração principal segue-se, porém, esta clausula de tempo:

"até que se liquidem os encargos a qué elas sirvam de garantia".

A situação começa, agora, a ser alterada. As taxas iam até 27 de abril de 1935, e cessavam automaticamente, nessa data, independente de decreto dos Estados. Agora, até que se liquidem os encargos a que sirvam de garantia. Prolongando-se a cobrança da taxa, agravou-se o onus que já asfixiava os produtores.

Os encargos a que a taxa serve de garantia, são, afinal, o emprestimo de 20 milhões. Mas, para resgate desse emprestimo, já se vem arrecadando, ha anos, a taxa de 5 shillings. $O$ emprestimo foi contraido antes da revolução de 1930, equivalente a 1.000.640:000\$000, conforme discurso eleitoral do Interventor paulista. E a taxa de exportação, para resgatá-lo, começou em dezembro de 1931. Quasi tres anos de arrecadação dadivosa. Não podia a taxa, a pretesto nenhum, ter outra aplicação legitima. Além disso, parte do emprestimo foi tomado em moeda nacional. E' facil a quem de direito, verificar, a qualquer momento, a quanto se acha reduzido o emprestimo. O Governo o sabe pelos balancetes que lhe devem ter sido entregues pelo Departamento, mez por mez, e nos quais vêm mencionada, discriminadamente, a 
aplicação dos 15 shillings, os saldos em caixa, o total de sacos de café comprados, eliminados ou utilisados, e em estoques. Nada mais ao alcance, pois, do que fixar o governo o quanto do emprestimo ainda em debito, e a que a taxa do cafié sirva ou serve de garantia. Ver-se-á, então, de pronto, quando vai cessar a arrecadação de tamanho onus ao produtor agricola. Em vez de a 27 de abril do ano proximo, ainda por alguns anos afóra.

Continua, ainda, o texto constitucional:

"respeitados os compromissos decorrentes dos convenios entre os Estados interessados".

Esta clausula antes de mais nada, não constava da proposta primitiva, aprovada pela Assembléa Constituinte. A proposta aprovada foi a emenda n. 1.955. La está ela no suplemento do Diario da Assembléa Nacional, de maio de 1934, pag. 211, art. 10, 3 :

"As taxas sôbre exportação, instituídas para a defesa de produtos agricolas, continuarão a ser arrecadadas, até que se liquidem os respetivas compromissos, sem que a importancia da arrecadação possa, no todo ou em parte, ter outra aplicação; e serão reduzidas, logo que se solvam os débitos em moeda nacional, a tanto quanto baste para o serviço de juros e amortisação dos empréstimos contraídos em moedas estrangeira".

Mais tarde, porém, como se pode verificar no suplemento do mesmo Diario, aos 29 de junho, pag. 19, o texto passa a ser o seguinte:

§ $3 .^{\circ}$ - "As taxas sôbre exportação, instituídas para a defesa de produtos agricolas, continuarão a ser arrecadadas, até que se liquidem os encargos a que elas sirvam de garantia, bem como os compromissos decorrentes de convenios entre os Estados interessados, sem que a importancia da arrecadação possa, no todo ou em parte, ter outra aplicação; e serão reduzidas, logo que se solvam os debitos em moeda nacional, a tanto quanto bastem 
para o serviço de juros e amortisação dos emprestimos contraidos em moeda estrangeira".

Por fim, a redação final do texto, como acima se transcreve.

Já vimos quais são, afinal, estes compromissos. Alguns já se consumaram com o tempo. Restam em vigor o das taxas de exportação de café o de sua aplicação exclusiva, o da restituição aos Estados interessados dos excessos entre a arrecadação da taxa e os encargos a que se destina, e o da aplicação do patrimonio do Departamento, quando se extinguir, no resgate do emprestimo de 20 milhões.

Outros compromissos já foram revogados, ou já caducaram, ou já não existem. Tal, por exemplo, o de cessar a taxa a 27 de abril de 1935, que foi revogado; tal o de pleitearem os Estados junto ao Governo Federal o restabelecimento da autonomia do Conselho Nacional do Café, que caducou com a criação do Departamento; tal o de entregar ao Instituto do Café de S. Paulo, para propaganda, cem mil sacos, que já não existem.

Continuemos, pois, a analise do texto constitucional. Agora, esta clausula:

"sem que a importancia da arrecadação possa, no todo ou em parte, ter outra aplicação".

Aqui, a inovação foi radical. E' a honesta compensação de prorogar, para além de 27 de abril do ano vindouro, a cobrança da taxa de exportação. Os Conselhos e o Departamento que os substituiu, admitiam ás claras tres aplicações para a taxa arrecadada:

1. - Compra de café para eliminação, propaganda e outros fins.

2." - Custeio de serviços do Conselho ou Departamento.

3." - Remessa das quantias necessarias ao serviço dos juros e amortização do emprestimo de 20 milhões de libras. 
Agora, porém, a Constituição, que como tal, revogou, evidentemente, as disposições em contrario, estatuiu, em tom sem réplica, que a importancia da arrecadação das taxas só pode, no todo ou em parte, ser aplicada na liquidaçẫo dos encargos a que sirvam de garantia.

Já não pode a taxa de exportação do café ser aplicada na compra de estoques, para eliminação, para propaganda, para conquista de novos mercados, seja para o que fôr. Já não pode ser aplicada para custear serviços do Departamento, mesmo em parte. Estes serviços, se o Governo lhes tiver a continuação por necessaria, pode atribui-los, por exemplo, ao Ministerio da Agricultura, com cujo orçamento os custeará. A importancia arrecadada das taxas de exportação de café não pode, absolutamente, sob nenhuma alegação, seja no todo, seja em parte, não pode ser aplicada senão no resgate do emprestimo, a que as taxas sirvam de garantia.

$\mathrm{E}$, mais, sobre as taxas de exportação continua o texto constitucional:

\begin{abstract}
"serão reduzidas, logo que se solvam os debitos em moeda nacional, a tanto quanto bastem para o serviço de juros e amortização dos emprestimos contraídos em moeda estrangeira".
\end{abstract}

Hoje, a taxa se acha fixada em $45 \$ 000$ por saco de café, que se exporte. Essa taxa, logo que se solvam os debitos em moeda nacional, que o Departamento contraíu, será reduzida ao necessario para pagar os juros e amortização dos emprestimos em moeda estrangeira para a defesa do café. Quais os debitos em moeda nacional? Qual o credor de tais debitos? O Banco do Brasil? Um balanço na caixa do Departamento iluminará o caminho percorrido, e deixará ver o caminho a vencer. Desde 10 de fevereiro de 1933, se acha em ação o Departamento, e recebeu ele a herança do Conselho Nacional, antes Conselho dos Estados Cafeeiros. E este data de 27 de abril de 1931, em que foi aprovado o convenio de tres dias antes. Desde essa época, vêm sendo 
cobrados 10 shillings por exportação de cada saco de café de 60 quilos, e mais 5 shillings desde 5 de dezembro de 1931. Ha, pois, quasi quatro anos que o Conselho e o Departamento, sucessor do Conselho, arrecadam, da exportação do café, centenas e centenas de mil contos, por ano, para custear o serviço de resgate do emprestimo de 20 milhões, para manter o equilibrio, no comercio do café, entre a of erta e a procura, e para o custeio de sua propria subsistencia. Hoje, pois os debitos dos emprestimos, em moeda nacional ou estrangeira, devem estar reduzidos a pouco.

Tomando por base os dados da Diretoria de Estatistica Economica e Financeira do Tesouro Nacional, publicados aos 4 de agosto de 1934, fica-se sabendo que, de maio a dezembro de 1931, foram exportados 11.191.102 sacos de café; de janeiro a dezembro de 1932, 11.935.244; de janeiro a dezembro de 1933, 15.459.309; de janeiro a julho de 1934, 7.626.417. Nesse periodo, isto é, da instalação dos Convenios até o fim do semestre ultimo, a exportação de café atingiu a 46.212.072 sacos.

Como de cada dois sacos, que se exportassem, receberam uma libra, esta exportação rendeu 23.106.036 libras.

Além dessa importancia, proveniente de taxa de 10 shillings, ainda se instituiu a taxa de 5 shillings. E esta, salvo pequena diferença, que não nos foi dado verificar por falta de dados oficiais, deve ter produzido, nesse periodo, mais de 9.000 .000 de libras.

Convertendo-se em moeda nacional, calculada a libra a $67 \$ 500$, pois fixaram em $45 \$ 000$ tres quartos dela, chega-se além desta cifra astronomica: 2.000.000:000\$000.

Só em 1933, a arrecadação da taxa de 15 shillings, segundo o Anuario Estatistico do Departamento Nacional do Café de 1934, importou em 711.588:358 $\$ 824$.

Mais, pois, de dois milhões de contos de réis, retirados á economia dos produtores de café, para salvá-los.

$\mathrm{E}$, acaso, se salvaram?

O Governo Federal, para lhes evitar a ruina definitiva, se viu na contingencia de expedir a lei do reajustamento. Se 
estavam em má situação economica, peor ficaram. A ação do Departamento não lhes recompoz as finanças. Além disto, a politica financeira que o Departamento vem exercendo, vai semeando a largas braçadas dois grandes males a que os governos e o povo não deram ainda a devida atenção. 0 primeiro é favorecer a concorrencia estrangeira contra o produto nacional nos mercados internacionais. E o segundo é instituir o sistema absurdo de, todo ano, produzir café, e queima-lo á custa do produtor. Em vez de empregar a abundancia da produção para vender mais e mais barato, e, com isto, destruir a concorrencia estrangeira, e assim equilibrar a oferta internacional em favor do produtor indigena, vai o Brasil queimando o café que produz, em beneficio do produtor estrangeiro.

Tem-se a impressão que os males já grangeados pelo Departamento do Café são maiores que os beneficios, já não se diga realizados, mas prometidos.

Para dizer tudo numa palavra, confessemos que, neste particular, foi a Constituinte de uma sabedoria acima de todo louvor. Cortou azas ao regime comunista, que se havia instaurado, desde 1931, no comercio do café. Mas estendeu, habilmente, ponte de transição, para entrar o paiz em normalidade economica. A proteção fiscal á industria do café estrangeiro, contra o nosso, na concorrencia internacional, vai cessar, com a diminuição progressiva da taxa, que a Constituição ordena, até a sua extinção total. De então em deante, os cafés de fóra, em competição com os brasileiros nos mercados externos, vão ficar em pé de egualdade. Cada paiz produtor se esforçará, então, por produzir o melhor pelo menor preço. E vencerá quem melhores condições naturais tiver de resistencia. Bem haja, pois, o $\S 3 .^{\circ}$, do art. 6. ${ }^{\circ}$, das Disposições Transitorias.

Interpretado o texto, e explicadas as razões de sua existencia, passemos a ver como se ha de ele aplicar com a lealdade que cumpre.

Tributos ha de finalidade geral, como o imposto de consumo ou de importação; e outros, de finalidade especifica, 
como a taxa judiciaria ou o selo de educação. A taxa sobre a exportação do café é um tributo de finalidade especifica.

Mas todos os tributos, sem exceções, se incorporam á receita nos termos do artigo 50 da Constituição. Não importa que tenham destino especial. 0 orçamento é uno. Preceitúa o artigo 5:

"O orçamento será uno, incorporando-se obrigatoriamente á receita todos os tributos, rendas e suprimentos de fundos, e incluindo-se discriminadamente na despesa todas as dotações necessarias ao custeio dos serviços publicos."

Na sua genese, a taxa de exportação do café não se podia, sob nenhum pretesto, incorporar aos orçamentos dos Estados que a criaram. Mas já uma vontade superior á dos Estados federados, a vontade do Governo Provisorio, ditou soberanamente outros rumos, avocando a si a solução ditatorial do problema. Os Estados começaram convidando o Governo Federal a participar, como fiscal, do plano de valorização que empreendiam. Mas, de convidado, entrou a União a deliberar, como senhor que não admite replica, substituindo, logo de entrada, o Conselho dos Estados pelo Departamento da União. A Constituinte, como órgão de soberania nacional, foi mais adeante. Ela podia tudo. E, no exercicio de seu poder supremo, determinou, contra o compromisso de honra dos Estados cafeeiros, incorporação obrigatória á receita de todos os tributos ou rendas.

Paralelamente, ordenou que se incluissem "discriminadamente, na despesa, todas as dotações necessarias ao custeio dos serviços publicos." Não importa que estes serviços sejam de natureza transitoria, como transitorio pode ser o tributo. Emquanto vigorar a taxa de exportação, haverá o serviço correspondente á sua cobrança, e á sua aplicação. $\mathrm{O}$ da arrecadação se fará pelas mesas de rendas nas Alfandegas, ou por agencias bancarias, como se faz hoje, 
por conta do Departamento. O do serviço de juros e amortização do emprestimo que a taxa de exportação garante, proceder-se-á como para os emprestimos federais, em cujo pagamento se empenha a probidade oficial.

$O$ que não se compreende, é que a arrecadação de um tributo, obrigatoriamente incorporado á receita (sem prejuizo de sua finalidade especifica), deixe de ser feita pelas agencias arrecadadoras, que o Governo já possue, ou por agencias que escolher.

Deante destas conclusões, rigorosamente constitucionais, perguntar-se-á: qual vem a ser a situação legal do Departamento Nacional do Café?

E' uma pessoa juridica cuja finalidade acabou. Já não pode arrecadar a taxa de exportação do café, porque, desde 16 de julho, ao entrar em vigor a Constituição, se incor porou á receita federal, sem prejuizo de sua finalidade exclusiva. Não pode continuar a manter os demais serviços que estiveram a seu cargo, porque já não tem com que pagá-los. A sua receita era a taxa de exportação do café, e esta não pode, no todo, ou em parte, ser aplicada, conforme determina o $\S 3 .^{\circ}$, art. $6 .^{\circ}$, das Disposições Transitorias, senão na liquidação dos emprestimos a que ela sirva de garantia. Como creatura, pois, já sem sopro de vida, o Departamento está, constitucionalmente, em liquidação forçada. Suas contas devem, por lei, estar prestadas cada mez. O saldo que tiver, em dinheiro ou mercadoria, se aplicará obrigatoriamente na liquidação final dos emprestimos em moeda, nacional ou estrangeira, de defesa do cafié. Todos os actos que não sejam de liquidação, praticados pelo Departamento, de 16 de julho para cá, são irritos e nenhuns. Se arrecadou a taxa de exportação daquela data até hoje, cumpre-lhe entregá-la ao Tesouro Nacional, para o serviço de resgate dos emprestimos, nos termos da Constituição.

Uma comissão de homens de senso, assistida por tecnicos, acertará facilmente as contas do Departamento. Devem 
elas estar prestadas, mez por mez, ao Ministerio da Fazenda, cujo ministro superintende a diretoria do Departamento. Recebeu este de taxa mais de dois milhões de contos. Se deve a bancos ou alhures, recebeu tambem o que deve. Somem-se as duas parcelas, e eis dinheiro que o Departamento entesourou. Tambem com a subrogação do emprestimo de 20 milhões, recebeu o café empenhado..... 16.500.000 sacos, hoje reduzido a onze milhões 614.200 sacos. Doutro lado, o Departamento comprou café para queimar. Na safra anterior, obrigou o produtor a lhe vender quarenta por cento da produção a trinta mil-réis o saco de 60 quilos. Comprou assim por menos do custo, uma extorsão inexplicavel. Já queimou como tem declarado, 32.176.859 sacos até 10 de outubro deste ano. Gastou tambem com os serviços que instituiu. Tudo isto lhe será levado a credito. O saldo que se verificar, será, obrigatoriamente, segundo compromisso decorrente dos convenios entre os Estados interessados, empregado no pagamento antecipado do emprestimo de vinte milhões.

No teor do contrato deste incrivel e celebre emprestimo, em que o espirito judeu tripudiou sobre a miseria de perdularios, o prazo para o seu pagamento é de dez anos, os juros de $7 \%$ o tipo 90 . O emprestimo rendeu menos do que era de esperar. As despesas foram enormes. Só com a impressão dos titulos, 25.000 libras, mais de mil contos de réis. Depois, uma diferença de cambio, na subdivisão em libras e dolares da parte de 12 milhões de libras, uma diferença de cambio de 836.548 libras, provavelmente 40 mil contos, perdidos por nós, numa magia de banqueiros.

Em cada ano, se vêm resgatando deste emprestimo dois milhões de libras. Já se foram mais de 4 anos. Hoje, a posição do emprestimo deve ser muito favoravel.

Para liquidá-lo, há o café do empenho. E mais o produto da taxa de 5 shillings, que, até epoca recente, rendeu, conforme dados oficiais, a respeitavel quantia de....... 485.296:057\$576. Esta importancia não podia ter outro des- 
tíno sinão resgatar o emprestimo, restituindo-se aos Estados interessados as sobras que se verificassem. São Paulo, porém, não recebeu, até agora, restituição nenhuma.

Fato é que, hoje, desde 16 de julho ultimo, o Departamento deixou de ter existencia constitucional. A sua extinção radical foi ato da Constituinte, soberana. Hoje, nem o Congresso ordinário pode revogar a extinção; por lei ordinária, não pode resuscitar o Departamento. A arrecadação da taxa tem de ser feita pelo Tesouro Federal, e a sua aplicação, no todo, ou em parte, só será para pagamento dos encargos a que a taxa sirva de garantia. Agora, só por uma reforma constitucional se poderá sair disto.

A não ser que se ouse violar, rosto a rosto, a Constituição em vigor, dando margem a que os prejudicados recorram ao poder judiciario, interprete ultimo da lei, não tem o Governo Federal outra saída, senão reconhecer a extinção constitucional do Departamento, tomar-lhe as contas, e aplicar o saldo, porventura existente, no pagamento das dividas contraídas para a defesa do café.

Em verdade, o texto da Constituição, cuja analise eis feita, foi coerente e fiel ao espirito que levou os Estados cafeeiros a crearem os Conselhos, o ultimo dos quais o Departamento absorveu. E não só isto, como é esse bem inspirado texto o que o bom senso aponta, o que reclama a justiça reparadora aos expropriados, o que, acima de tudo, impõe o interesse nacional, a previdencia de sua administração, a segurança e a firmeza de seu futuro. 